\title{
Making Strategic Supply Chain Capacity Planning more Dynamic to cope with Hyperconnected and Uncertain Environments
}

\author{
Raphaël OGER ${ }^{1,2}$, Frédérick BENABEN ${ }^{1,2}$, Matthieu LAURAS ${ }^{1,2}$, Benoit MONTREUIL ${ }^{2}$ \\ ${ }^{1}$ Industrial Engineering Center, IMT Mines Albi, Institut Mines-Télécom, Albi, France \\ \{raphael.oger, matthieu.lauras, frederick.benaben\}@ mines-albi.fr \\ ${ }^{2}$ Physical Internet Center, ISYE School, Georgia Institute of Technology, Atlanta, USA \\ benoit.montreuil@isye.gatech.edu
}

\begin{abstract}
Public and private organizations cope with a lot of uncertainties when planning the future of their supply chains. Additionally, the network of stakeholders is now intensely interconnected and dynamic, revealing new collaboration opportunities at a tremendous pace. In such a context, organizations must rethink most of their supply chain planning decision support systems. This is the case regarding strategic supply chain capacity planning systems that should ensure that supply chains will have enough resources to profitably produce and deliver products on time, whatever hazards and disruptions. Unfortunately, most of the existing systems are unable to consider satisfactorily this new deal. To solve this issue, this paper develops a decision support system designed for making strategic supply chain capacity planning more dynamic to cope with hyperconnected and uncertain environments. To validate this decision support system, two industrial experiments have been conducted with two European pharmaceuticals and cosmetics companies.
\end{abstract}

\section{Introduction}

Modern supply chains are dealing with a highly uncertain and dynamic environment. Considering these characteristics is as vital as challenging for public and private organizations when it comes to planning the future of their supply chains. Considering uncertainty is crucial for supply chain planning because it is based on forecasts which are by essence uncertain [1]. Additionally, being as responsive as the environment dynamicity is the key for taking advantage of new collaboration opportunities.

The scientific literature as well as the recent COVID-19 pandemic show that uncertainty-driven supply chain management is the new normal [1]-[9].
However, decision support systems (DSS) found in the literature are not appropriate for dealing with uncertainty because assume restrictive hypotheses which neglect or consider uncertainty in a too simple way [10]-[14]. The scientific literature also shows that opportunity-driven supply chain management is an order winning capability [5], [15]-[19]. However, DSS found in the literature do not support the ambition of considering the number of collaboration opportunities at the pace they appear in the supply chain environment [20]-[22].

There are several viewpoints to define DSS, some authors limit the definition to a computer system while others also include the decision-making process that makes use of the computer system [23]. The second mindset is considered in this paper, considering a DSS as the combination of an information system as well as a decision-making process.

The objective of the research project this paper is part of is to overcome the limitations of existing DSS regarding their ability to support uncertainty- and opportunity-driven supply chain management, and more precisely Strategic Supply Chain Capacity Planning (SSCCP). In other words, it is to design a DSS that will make SSCCP more dynamic to cope with hyperconnected and uncertain environments. A conceptual framework of this SSCCP DSS has already been introduced by Oger et al. [24]. It provides guidelines for designing an uncertainty- and opportunity-driven SSCCP DSS. The current paper expands on the conceptual framework by introducing an SSCCP information system following the conceptual framework guidelines.

The second section describes the review of existing computerized solutions that could automatically identify the supply chain capacity plan alternatives as well as the associated assessment model. The third section introduces the SSCCP information system proposal. The fourth section describes the validation of the proposal through two industrial experiments. 
Finally, the fifth section concludes the paper and highlights avenues for future research.

\section{Literature review}

\subsection{Objectives}

According to the existing SSCCP DSS conceptual framework this paper expands [24], the following two activities of the proposed SSCCP decision-making process should be fully automated: "generate an assessment model compatible with all what-if scenarios" and "assess what-if scenarios".

In searching for SSCCP assessment models, it was observed that existing modeling approaches (e.g., optimization, simulation, and heuristics) require the users to provide a model of the existing or potential supply chains they want to assess [12], [13], [25]-[27]. In addition, when implemented in existing information systems (e.g., ERP, APSs, and spreadsheets), these approaches are very time-consuming [28].

An idea emerged from this observation: to change the mindset from modeling the known strategic supply chain capacity plan alternatives and assessment model to automatically deducing it by means of a computerized solution. Therefore, this idea implied a literature review about existing computerized solutions that could automatically identify the supply chain capacity plan alternatives as well as the associated assessment model. Finally, the undertaken literature review was a little bit more general and focused on searching for existing solutions to automatically identify potential supply chains and associated stakeholders (encompassing strategic supply chain capacity plan alternatives and assessment model).

\subsection{Methodology and results}

This literature review was conducted according to a systematic literature review methodology [6]. The scope of the literature review was defined in terms of searched databases, keywords, combinations of keywords, requests sent to search engines, and the search engines configuration. Two databases were used: Web of Science (WOS) and Google Scholar. Selected keywords fall into two groups which then drive the keyword combinations. The first group of keywords includes terms used to describe the type of system studied: supply chain, logistics network, supplier, subcontractor. The second group of keywords includes terms used to describe the interaction with the studied system that could be relevant for identifying potential supply chains and associated stakeholder and by extension for building a dynamic SSCCP DSS: discovery, identification, deduction, hyperconnection. The search included all possible combinations of two keywords from distinct groups and their alternative spelling (WOS example : "TITLE: (("supply chain*" OR "logistic* network*" OR "supplier*” OR "subcontractor*”) AND (discover* OR identifi* OR deduc* OR hyperconnect*))"). For both databases investigated, the requests were focused on paper titles and all publication years were considered. For the search request sent to Google Scholar, citations and patents were excluded. The requests brought up 196 papers from WOS and 805 papers from Google Scholar. The next step was to select the papers that seemed relevant enough, according to the literature review objective, to be investigated by reading the entire paper. This was done in two elimination phases: a first elimination phase based on the titles, and a second elimination phase based on the abstracts. Papers were considered probably relevant when they were understood as probably being about the identification of supply chain stakeholders, of supply chain options, or supply chain solutions. For example, several papers used product identification terminology in the context of product traceability and supply chain visibility, which is not relevant for this study. Overall, 69 papers were tagged as potentially pertinent after the title-based phase and 21 after the abstract-based phase. The final paper selection step was based on a full reading of the potential papers, which resulted in 18 papers chosen to be included in the literature review.

The first literature review result is that all the reviewed papers cover supply chain stakeholder identification and one decision type: supplier selection [28]-[45]. However, only a single paper explicitly treats the identification of supply chain capacity plan alternatives: Fritz et al. [28]. The team led by Ameri and McArthur produced most of the papers on supply chain stakeholder identification [29]-[34].

Except for the paper by Fritz et al. (2018), which introduces a human-oriented methodology for supply chain stakeholder identification, all the other 17 papers introduce or discuss computerized methods to partially automate the identification of supply chain stakeholders. Two main types of contributions were identified for automating the identification of supply chain stakeholders. The first corresponds to contributions for gathering information about supply chain stakeholders' capabilities from distributed data sources (e.g., web and peer-to-peer) and consolidating them into a centralized data source. The second corresponds to contributions for matching supply chain stakeholders' capabilities with buyers' requirements from data stored in a centralized data source. For the first type of contribution, the following approaches were found for gathering and consolidating information about supply chain stakeholders' capabilities from distributed data sources: website 
search [36], dynamic forms completed by stakeholders [38], [39], and peer-to-peer platform software [45]. For the second type of contribution, the following approaches were found for matching supply chain stakeholders' capabilities with buyers' requirements stored in a centralized data source: semantic reconciliation approaches to find matches [29]-[34], [38]-[41], [43], ontologies to structure information [29]-[34], [38]-[41], [43], [44], and semantic clustering of supply chain stakeholders' capabilities in a classification tree to classify and retrieve capabilities [42]. As part of the second type of contributions, the report by Fenves et al. [37] from the U.S. Department of Commerce and the National Institute of Standards and Technology (NIST) highlights the need for a taxonomy to share a common terminology among supply chain stakeholders to support supply chain stakeholder identification.

In addition to the contributions introduced by the reviewed papers, some mention existing online services provided by businesses to match supply chain stakeholders' capabilities with buyers' requirements from a centralized data source (e.g., www.alibaba.com, www.ec21.com, www.mfg.com) [40], [41], [44]. They are defined by authors as "e-marketplace" or "esourcing portals".

Regarding supply chain capacity plan alternative identification, Fritz et al. [28] introduce a methodology called Supply Chain-Oriented Process to Identify Stakeholders (SCOPIS) to identify supply chain stakeholders and supply chain capacity plan alternatives. It is an approach centered on the production of a product or service. Their proposal provides an organizational human-oriented process to identify supply chain stakeholders and supply chain capacity plan alternatives. However, it is a manual process; no computerized method is mentioned to support it. Fritz et al. [28] concludes that one of the key limitations of their proposal is the high use of resources and time consumption. This is a limitation for companies who want to perform it frequently to support their decisions.

\subsection{Conclusions and research question}

All the computerized methods identified during the literature review, both from the scientific literature and existing business solutions, are designed to identify supply chain stakeholders and supply chain options for one-to-one relationships between supply chain stakeholders. None of them introduces research on computerized methods for supply chain plan identification encompassing several supply chain levels, nor on an associated assessment model. So, these solutions would be very limiting for designing an opportunity-driven SSCCP DSS.
In addition, the only paper from the literature review introducing research on supply chain capacity plan identification proposes a human-centered approach described as resource- and time-consuming [28]. So, the proposal by Fritz et al. [28] does not meet with the SSCCP DSS dynamicity requirements.

Finally, no computerized method to automatically identify supply chain plan alternatives and associated assessment models was found. In other words, no computerized solution was found in the literature to implement a SSCCP information system following the SSCCP conceptual framework guidelines. This means not being able to fully build an uncertainty- and opportunity driven SSCCP DSS from existing computerized methods. This creates a gap between the literature and the SSCCP DSS conceptual framework requirements. This gap led to the following research question: how to design a SSCCP DSS complying with the conceptual framework guidelines introduced by Oger et al. [24], and especially the automation requirements?

Therefore, the choice was made to focus the innovation efforts on designing a computerized information system that automates the identification and evaluation of strategic supply chain capacity plan alternatives made possible by supply chains stakeholders (i.e., opportunity-driven), including the consideration of the multitude of uncertainties (uncertainty-driven). The following section describes the resulting SSCCP IS proposal.

\section{Contribution: a decision support system for making strategic supply chain capacity planning more dynamic}

To answer the research question, an SSCCP DSS was designed by proposing solutions that comply with the guidelines provided by the SSCCP DSS conceptual framework introduced by Oger et al. [24]. The SSCCP DSS is composed of a SSCCP information system as well as a SSCCP decision-making process. The main objective of this paper is to introduce the SSCCP information system proposal; therefore, the emphasis is put on the information system. Figure 1 provides an overview of the SSCCP DSS with a focus on the information system modules as well as information exchange with the decision-making process stakeholders. The SSCCP information system corresponds to an innovative computerized method for supporting companies in making SSCCP decisions by providing automation features for identifying and assessing strategic supply chain capacity plan alternatives made possible by a set of supply chains stakeholders. The SSCCP information system operating principles are inspired from model-driven 
engineering principles [46], [47], including metamodel-based algorithms and model transformations. The SSCCP information system modules are described in the following subsections.

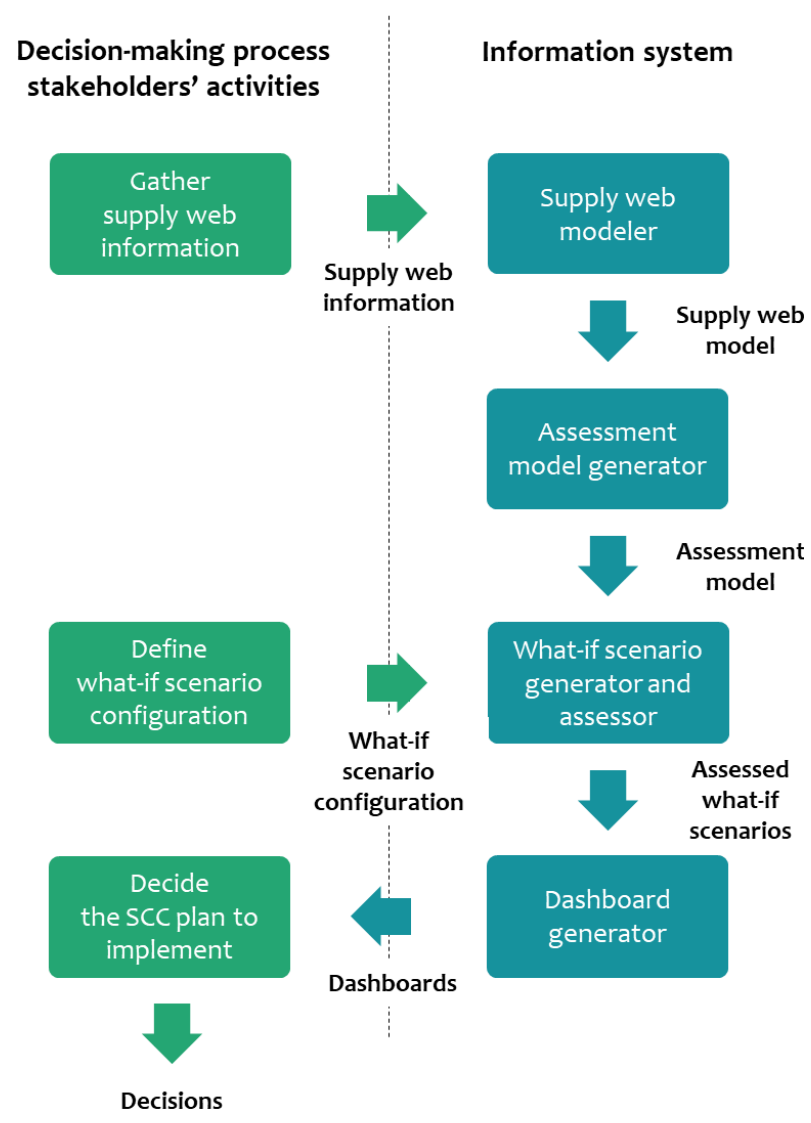

Figure 1: SSCCP DSS overview focusing on the information system modules and their interactions with decision-making process stakeholders

\subsection{Supply web modeler}

The first module is called the "supply web modeler." The term "supply web" is defined here as a set of identified active and potential supply chain stakeholders". This module takes information from the supply web as inputs to create a model of the supply web that will then be used by the two other modules. It is composed of the following two building blocks: First, a supply web metamodel designed to structure supply web knowledge (Figure 2). The objective of this supply web metamodel is to support the automation of other modules that use this information by relying on the structure of the information guaranteed by the metamodel. Second, two types of user interfaces (webbased and spreadsheet) and associated algorithms that allow users to create the model of the supply web according to the metamodel.

\subsection{Assessment model generator}

The second module is called the "assessment model generator." This second module takes the supply web model created by the first module as an input to create a generic assessment model. "Assessment model" should be understood to be a model (e.g., an optimization model or a spreadsheet model) that can be used to assess the supply chain performance of a specific scenario by providing inputs describing this scenario (e.g., by filling spreadsheet cells with values). In addition, "generic" means that it is compatible with all scenarios of potential futures (i.e., what-if scenarios) that can be deduced from the supply web model information. Therefore, this generic assessment model can be used to assess all what-if scenarios deduced from the supply web model information.

The created assessment model is composed of two elements: first, a potential supply chain map defined as the "graph of interlaced supply options forming a map containing all potential supply chains made possible by the supply web stakeholders for fulfilling the demand". Second, a set of key performance indicator (KPI) formulas that are associated with both the potential supply chain map as well as the supply web model. To obtain this result, the "assessment model generator" is composed of three building blocks respectively described in the following three sub-subsections.

\subsubsection{Potential supply chain map metamodel}

The first building block of the assessment model generator is a metamodel to structure the potential supply chain map information. This metamodel is inspired from process modeling and the research results on the collaborative business processes described by Montarnal et al. [48]. It is a simplified version of the Business Process Model and Notation (BPMN) [49]. The choice was made to represent the supply chain options as a process inspired from BPMN for two main reasons: first, it allows for making the analogy between the sequence of activities of a process and the physical flows of a supply chain represented by the edges. Second and most importantly, it makes possible the description of the physical flows with logical links represented by gateways describing when a physical flow is a choice (inclusive gateways) or a necessity (parallel gateways). This metamodel is composed of the following 7 types of nodes having specific meanings to describe the potential supply chain map: start event, end event, activity, opening inclusive gateway, opening parallel gateway, closing inclusive gateway, and closing parallel gateway. 


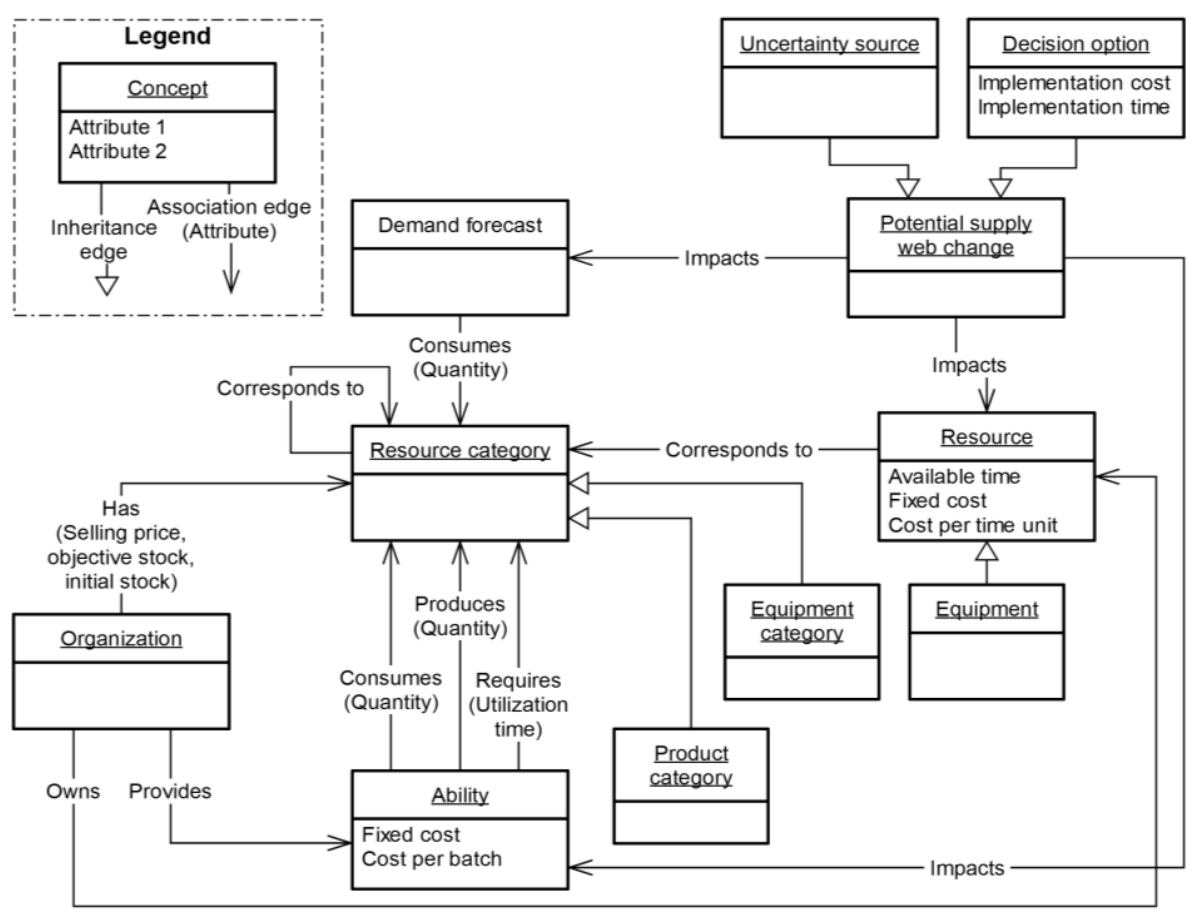

Figure 2: Supply web metamodel designed to make the creation of metamodel-based algorithms possible It is used within two DSS modules: "assessment model generator" and "what-if scenario generator and assessor

\subsubsection{Potential supply chain map generator}

The second building block of the assessment model generator is an algorithm designed to automatically deduce the first component of the assessment model: the potential supply chain map. The algorithm uses the structure of the supply web metamodel to exploit the supply web models and automatically create the potential supply chain map model according to the potential supply chain map metamodel. It is a model transformation, as defined by Benaben et al. [50], from the supply web point of view to the potential supply chain map point of view. In other words, it transforms the knowledge of the supply web into knowledge of the potential supply chain map. This is a key component of the SSCCP DSS proposal. One of the simplest possible illustrative examples of a potential supply chain map containing all types of nodes is given in Figure 3.

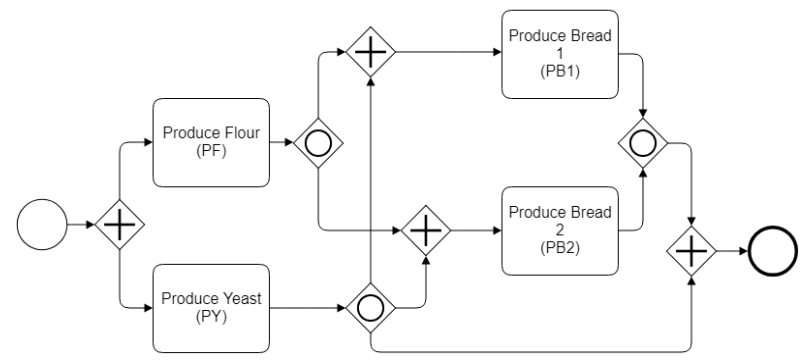

Figure 3: One of the simplest potential supply chain map examples containing all types of nodes

\subsubsection{KPI formulas generator}

The third building block of the assessment model generator is an algorithm designed to automatically deduce KPI formulas for several elements of both the supply web and the potential supply chain map models. The algorithm takes both the supply web and the potential supply chain map models as inputs and updates them by adding KPI formulas. The KPI formulas correspond to formulas that contain parameter identifiers rather than their values. The objective of having parameter identifiers rather than values is to have formulas that are compatible with all what-if scenarios, because parameter identifiers can be replaced by their value according to the considered what-if scenario. The main types of KPI for which a formula is deduced are synthesized in Table 1, organized according to the metamodel and node or edge they are associated with.

The KPI formula deduction algorithm first creates a demand forecast formula for each resource category having at least one associated demand forecast in the supply web model. It associates these formulas with the end event. These formulas that are associated with the end event are created by aggregating the demand forecasts of the supply web model per resource category. Second, the KPI formula deduction algorithm propagates the demand forecast formulas backwards along the potential supply chain map to create the following formulas associated with each activity: gross 
requirements, net requirements, and production objectives. Third, after deducing these first four types of KPI formulas, the KPI deduction algorithm uses these formulas along with information from the supply web to deduce all the other formulas mentioned in Table 1.

The KPI formulas are deduced for the lowest organizational level of detail of the metamodel so that they can be aggregated to get a higher-level view. For example, aggregating (i.e., summing) the "revenue relying on it" KPI formulas of all resources of an organization gives the formula of the revenue of the corresponding organization. And aggregating (i.e., summing) the "revenue relying on it" KPI formulas among all organizations gives the formula of the revenue of the entire supply web scope considered. The same approach can be made for the "revenue relying on it" of the activities as well as the "Total utilization cost" of the resources and activities.

Table 1: Main key performance indicators for which a generic formula is deduced

\begin{tabular}{|c|c|c|}
\hline Metamodel & Node / Edge & Key performance indicator \\
\hline \multirow{5}{*}{$\begin{array}{l}\text { Potential } \\
\text { supply } \\
\text { chain } \\
\text { map }\end{array}$} & \multirow{5}{*}{ Activity } & Gross requirement \\
\hline & & Net requirement \\
\hline & & Production objective \\
\hline & & Total utilization cost \\
\hline & & Revenue relying on it \\
\hline \multirow{6}{*}{$\begin{array}{l}\text { Supply } \\
\text { web }\end{array}$} & \multirow{3}{*}{$\begin{array}{l}\text { "Has" from } \\
\text { Organization } \\
\text { to Resource } \\
\text { category }\end{array}$} & Utilization time required \\
\hline & & Available time \\
\hline & & Revenue relying on it \\
\hline & \multirow{3}{*}{$\begin{array}{l}\text { Resource } \\
\text { (Equipment) }\end{array}$} & Utilization time required \\
\hline & & Total utilization cost \\
\hline & & Revenue relying on it \\
\hline
\end{tabular}

\subsection{What-if scenario generator and assessor}

The third module is called the "what-if scenario generator and assessor." This third module takes three inputs: the supply web model created by the first module, the assessment model created by the second module, and the what-if scenario configuration provided by users. The output of this module is the list of assessed what-if scenarios, along with their assessment results. This module is composed of two building blocks respectively described in the following two sub-subsections.

\subsubsection{What-if scenario generator}

The first building block of the what-if scenario generator and assessor is an algorithm that collects the supply web model created by the first module as well as request users to provide the what-if scenario configuration, and then generates the list of what-if scenarios to assess.

The what-if scenario configuration aims at defining the behavior the algorithm will have when processing the different decision and uncertainty variables that are the essence of what-if scenarios. There are three types of decision and uncertainty variables that lead to whatif scenarios. The first two are part of the supply web metamodel (Figure 2): the decision options and the uncertainty sources. The third one is part of the potential supply chain map metamodel and is explained thereafter: the inclusive Closing Gateways.

The potential supply chain map created by the assessment model generator contains all possible flows of physical goods. Within this potential supply chain map, there can be inclusive Closing Gateways representing supply options. So, for each inclusive Closing Gateway, there is a supply option to choose. The organization owning the downstream activity must decide on the distribution of its supplies among the organizations owning the upstream activities. Therefore, different decisions according to these gateways imply different scenarios.

In addition, this choice must be made for each period that must be assessed. Therefore, the what-if scenario configuration contains the following information: time granularity of the supply web model, time horizon to consider, threshold regarding the number of decision options to be considered simultaneously, threshold regarding the number of uncertainty sources to be considered simultaneously, and for each OR Closing Gateway and each period: the sets of supply options to consider.

\subsubsection{What-if scenarios assessor}

The second building block of the what-if scenario generator and assessor is an algorithm that assesses all what-if scenarios of the list generated by the previous algorithm. It takes the following three elements as inputs: the supply web model, the assessment model, and the list of what-if scenarios to assess.

For each what-if scenario to assess, the algorithm takes the KPI formulas of the assessment model and replaces the parameter identifiers by their values resulting from the combination of decision options (including supply options) and uncertainty sources of this specific what-if scenario. To obtain the value of each parameter, it takes its initial forecasted value from the supply web model and applies the impact of all uncertainty sources and decision options considered in the what-if scenario. Then, it computes the KPI formulas which results in the set of KPI values for each what-if scenario.

Finally, this building block structures the what-if scenario assessment results so they can be used by the 
dashboard generator. This algorithm must be adapted to the input requirements of the following module (the dashboard generator). In this research project the whatif scenario assessment results are structured as a JavaScript Object Notation (JSON) file.

\subsection{Dashboard generator}

The fourth module is called the "dashboard generator." This fourth module takes the what-if scenario assessment results generated by what-if scenario generator and assessor module. It has been considered that the dashboard generation feature would not be part of the scientific contributions of this research project. Therefore, an existing business intelligence software has been used to process and display the what-if scenario assessment results: Tableau ${ }^{\circledR}$ [51]. Consequently, the JSON file format was chosen for storing the what-if scenario assessment results as the format must be compatible with the chosen software.

\section{Validation: two industrial experiments}

The approach has been applied and challenged with two industrial experiments with two pharmaceutical and cosmetics companies. The first was with the cosmetics company and focuses on decisions related to the production capacity of the company's suppliers of bottles. The second was with the pharmaceutical company and focuses on decisions related to the internal production capacity of the company. The following two subsections briefly describe both experiments, and the third one discusses the results.

\subsection{First industrial experiment}

The objective of this first use case was to increase the visibility the cosmetics company has about the supply chain alternatives enabled by its suppliers of bottles and about their capacity investments options. It includes discovering, assessing, and visualizing the supply chain capacity plan alternatives. The company gathered information about capabilities of its network of suppliers of bottles, about the market demand forecasts, and about supply chain options and uncertainty sources. All that information has been used to create the supply web model according to the metamodel introduced in the previous section. The model contains 250 nodes and more than twice as many edges describing the structure of the supply web.

Then, the assessment model generator deduced the potential supply chain map, which contained 84 nodes, and associated key performance indicators formulas. Next, the what-if scenario assessment generator module has been configured with a time granularity of years over five years, to consider what-if scenarios combining a maximum of one decision option and one uncertainty source simultaneously, and three supply configurations have been set. Finally, 1140 scenarios were generated, assessed, and analyzed.

\subsection{Second industrial experiment}

The objective of this second experiment was to increase the visibility the pharmaceutical company has about its internal capabilities for producing its entire portfolio of products and about its capacity investments options. It includes discovering, assessing, and visualizing its internal capacity plan alternatives. The company gathered information about its internal production capabilities involved in the production processes, about the market demand forecasts, and about supply chain options and uncertainty sources. All that information has been used to create the supply web model that contains 1451 nodes and more than twice as many edges describing the structure of the supply web.

Then, the assessment model generator deduced the potential supply chain map, which contained 396 nodes, and associated key performance indicators formulas. Next, the what-if scenario assessment generator module has been configured with a time granularity of years over four years, to consider what-if scenarios combining a maximum of one decision option and one uncertainty source simultaneously, and only one supply configurations have been set because the use case does not require supply decisions. Finally, 24 scenarios were generated, assessed, and analyzed.

\subsection{Discussion: results and findings}

The validity of the results has been verified in two different ways: first manually looking at the structure of the potential supply chain graph model and associated performance indicators formulas. Second by evaluating several scenarios both using the software and a manual evaluation and comparing the results.

From a business perspective, the following three benefits of the contribution have been confirmed: first, it enables to automatically identify all possible supply chain alternatives described by the potential supply chain map, without having to manually draw the supply chains. It means that changes in the supply web structure that might have consequences at several levels of the supply chain only have to be specified once in the supply web model and then the consequences are automatically deduced. Second, thanks to the automated generation, it enables supply chain managers and their teams to generate and analyze more strategic supply chain capacity plan alternatives that they were used to. Third, it is seen by practitioners as an opportunity to involve product development teams in the decision-making process and make SSCCP part of the product development process. In other words, it is seen as an opportunity to easily 
enable the product development teams to consider the impacts on the supply chains when designing new products. The product innovation options can be introduced into the supply web model of the SSCCP DSS and so their potential impacts on the supply chains can be assessed.

\section{Conclusion and research avenues}

The objective of the research project this paper is to make SSCCP more dynamic to cope with hyperconnected and highly uncertain environments. Results from Oger el al. [24] as well as the literature review of this paper lead to the conclusion that existing DSS are not satisfying enough to reach this objective. Mainly because existing DSS are too time consuming when it comes to assessing a multitude of what-if scenarios resulting from the combination of the multitude of decision options and uncertainty sources. So, there is a gap between the needs and existing solutions. Oger el al. [24] introduces a SSCCP DSS conceptual framework providing guidelines for designing a SSCCP DSS that would fill this gap. Based on the guidelines provided by this SSCCP DSS conceptual framework, the current paper introduces a SSCCP DSS designed accordingly.

Two industrial experiments conducted with two pharmaceuticals and cosmetics companies resulted in a first validation of the SSCCP DSS. Both experiment results demonstrate that the SSCCP DSS proposal is a step towards making SSCCP more dynamic to cope with hyperconnected and uncertain environments. Companies confirmed that it enables them to consider many more what-if scenarios (i.e., decision options and uncertainty sources) that they were used to. Based on the SSCCP DSS proposal and experiment results, some avenue for future research have been identified and are described thereafter.

The first avenue is about consolidating the validation of the contribution. The SSCCP DSS is designed to be usable for any type of supply web and associated supply chain. However, an experiment was focused on decisions related to the production capacity of the company's suppliers, and the other on decisions related to the company's internal production capacity. Performing experiment combining both internal and external visions, and in different business contexts would consolidate the validation of the proposal.

The second avenue for future research is about enhancing the proposal. The SSCCP DSS provides performance results for each assessed what-if scenario. However, it does not provide recommendations that would guide decision makers towards the best strategic supply chain capacity plan alternatives they could choose to implement. The design of this feature was left to people by using the business intelligence software. To go further in supporting companies making SSCCP decisions, it would be relevant to complement the SSCCP DSS with a module that automates decision recommendations.

Finally, the third avenue for future research is about enhancing the SSCCP DSS by proposing a formalized and detailed SSCCP decision-making process.

\section{References}

[1] W. J. Hopp and M. L. Spearman, Factory Physics: Third Edition. Waveland Press, 2011.

[2] J. G. A. J. van der Vorst and A. J. M. Beulens, "Identifying sources of uncertainty to generate supply chain redesign strategies," Int. J. Phys. Distrib. Logist. Manag., vol. 32, no. 6, pp. 409430, Aug. 2002, doi: $10.1108 / 09600030210437951$.

[3] R. Narasimhan and S. Talluri, "Perspectives on risk management in supply chains," J. Oper. Manag., vol. 27, no. 2, pp. 114-118, Apr. 2009, doi: 10.1016/j.jom.2009.02.001.

[4] G. T. M. Hult, C. W. Craighead, and D. J. Ketchen Jr., "Risk Uncertainty and Supply Chain Decisions: A Real Options Perspective: Risk Uncertainty and Supply Chain Decisions," Decis. Sci., vol. 41, no. 3, pp. 435-458, Aug. 2010, doi: 10.1111/j.1540-5915.2010.00276.x.

[5] M. Christopher and M. Holweg, "Supply chain 2.0 revisited: a framework for managing volatility-induced risk in the supply chain," Int. J. Phys. Distrib. Logist. Manag., vol. 47, no. 1, pp. 2-17, Jan. 2017, doi: 10.1108/IJPDLM-092016-0245.

[6] C. Colicchia and F. Strozzi, "Supply chain risk management: a new methodology for a systematic literature review," Supply Chain Manag. Int. J., vol. 17, no. 4, pp. 403-418, Jun. 2012, doi: 10.1108/13598541211246558.

[7] E. Simangunsong, L. C. Hendry, and M. Stevenson, "Supply-chain uncertainty: a review and theoretical foundation for future research," Int. J. Prod. Res., vol. 50, no. 16, pp. 44934523, Aug. 2012, doi: 10.1080/00207543.2011.613864.

[8] M. J. Sáenz and E. Revilla, "Creating more resilient supply chains," MIT Sloan Manag. Rev., vol. 55, no. 4, pp. 22-24, 2014.

[9] M. S. Golan, L. H. Jernegan, and I. Linkov, "Trends and applications of resilience analytics in supply chain modeling: systematic literature review in the context of the COVID-19 pandemic," Environ. Syst. Decis., p. 1, 2020.

[10] M. Goetschalckx, C. J. Vidal, and K. Dogan, "Modeling and design of global logistics systems: A review of integrated strategic and 
tactical models and design algorithms," Eur. J. Oper. Res., vol. 143, no. 1, pp. 1-18, Nov. 2002, doi: 10.1016/S0377-2217(02)00142-X.

[11] M. J. Meixell and V. B. Gargeya, "Global supply chain design: A literature review and critique," Transp. Res. Part E Logist. Transp. Rev., vol. 41, no. 6, pp. 531-550, Nov. 2005, doi: 10.1016/j.tre.2005.06.003.

[12] J. Mula, R. Poler, J. P. García-Sabater, and F. C. Lario, "Models for production planning under uncertainty: A review," Int. J. Prod. Econ., vol. 103, no. 1, pp. 271-285, 2006.

[13] H. Stadtler, C. Kilger, and H. Meyr, Eds., Supply Chain Management and Advanced Planning: Concepts, Models, Software, and Case Studies, 5th ed. Berlin Heidelberg: Springer-Verlag, 2015.

[14] J. Pires Ribeiro and A. Barbosa-Povoa, "Supply Chain Resilience: Definitions and quantitative modelling approaches - A literature review," Comput. Ind. Eng., vol. 115, pp. 109-122, Jan. 2018, doi: 10.1016/j.cie.2017.11.006.

[15] B. Montreuil, "Toward a Physical Internet: meeting the global logistics sustainability grand challenge," Logist. Res., vol. 3, no. 2-3, pp. 7187, May 2011, doi: 10.1007/s12159-011-0045-x.

[16] B. Montreuil, "The Physical Internet: A Conceptual Journey, Keynote Presentation," 2nd Int. Phys. Internet Conf. IPIC Paris Fr., Jul. 2015.

[17] B. Montreuil, R. D. Meller, and E. Ballot, "Physical internet foundations," in Service Orientation in Holonic and Multi Agent Manufacturing and Robotics, Springer, 2013, pp. 151-166.

[18] S. A. Melnyk, R. Narasimhan, and H. A. DeCampos, "Supply chain design: issues, challenges, frameworks and solutions," Int. J. Prod. Res., vol. 52, no. 7, pp. 1887-1896, Apr. 2014, doi: 10.1080/00207543.2013.787175.

[19] B. Fleischmann and A. Koberstein, "Strategic network design," in Supply Chain Management and Advanced Planning: Concepts, Models, Software, and Case Studies, 5th edition., Berlin: Springer, 2015, pp. 107-123.

[20] R. Olsson, "In search of opportunity management: Is the risk management process enough?," Int. J. Proj. Manag., vol. 25, no. 8, pp. 745-752, Nov. 2007, doi: 10.1016/j.ijproman.2007.03.005.

[21] L. A. de Santa-Eulalia, S. D'Amours, J.-M. Frayret, C. C. Menegusso, and R. C. Azevedo, "Advanced Supply Chain Planning Systems (APS) Today and Tomorrow," Supply Chain
Manag. - Pathw. Res. Pract., Aug. 2011, doi: 10.5772/19098.

[22] D. Pinon, R. Oger, and M. Lauras, "Supply Chain Evolution and Supply Chain Capability Planning Methodologies: A Review and Gap Identification," presented at the 7th International Conference on Information Systems, Logistics and Supply Chain (ILS 2018), Lyon, France, 2018, doi: https://hal-mines-albi.archivesouvertes.fr/hal-01886020.

[23] D. Power, Decision support systems: concepts and resources for managers. Santa Barbara, CA, USA: Greenwood Publishing Group, 2002.

[24] R. Oger, M. Lauras, B. Montreuil, and F. Benaben, "A decision support system for strategic supply chain capacity planning under uncertainty: conceptual framework and experiment," Enterp. Inf. Syst., vol. 0, no. 0, pp. 1-45, Jul. 2020, doi: 10.1080/17517575.2020.1793390.

[25] T. F. Wallace and R. A. Stahl, Sales and Operations Planning The How-To Handbook, 3rd ed. T. F. Wallace \& Company, 2008.

[26] H. I. Calvete, C. Galé, and L. Polo, "Integrated Supply Chain Planning: A Review," in Modeling and Simulation in Engineering, Economics and Management, Springer, 2016, pp. 92-103.

[27] A. Martel and W. Klibi, Designing valuecreating supply chain networks. Berlin: Springer, 2016.

[28] M. M. C. Fritz, R. Rauter, R. J. Baumgartner, and N. Dentchev, "A supply chain perspective of stakeholder identification as a tool for responsible policy and decision-making," Environ. Sci. Policy, vol. 81, pp. 63-76, Mar. 2018, doi: 10.1016/j.envsci.2017.12.011.

[29] F. Ameri, C. McArthur, B. Asiabanpour, and M. Hayasi, "A web-based framework for semantic supplier discovery for discrete part manufacturing," in Proceedings of NAMRI/SME, 2011, vol. 39.

[30] F. Ameri and C. McArthur, "Semantic rule modelling for intelligent supplier discovery," Int. J. Comput. Integr. Manuf., vol. 27, no. 6, pp. 570-590, Jun. 2014, doi: 10.1080/0951192X.2013.834467.

[31] F. Ameri and C. McArthur, "An Experimental Evaluation of a Rule-Based Approach to Manufacturing Supplier Discovery in Distributed Environments," in ASME Proceedings | 31st Computers and Information in Engineering Conference, Part $A$ and B, Washington, DC, USA, 2011, vol. 2, pp. 1121-1133, doi: 10.1115/DETC2011-47768. 
[32] F. Ameri and C. McArthur, "An Ontological Approach to Manufacturing Supplier Discovery in Virtual Markets," in ASME Proceedings 30th Computers and Information in Engineering Conference, Parts $A$ and B, Montreal, Quebec, Canada, Aug. 2010, vol. 3, pp. 435-447, doi: 10.1115/DETC2010-28179.

[33] C. McArthur and F. Ameri, "Knowledge Representation for Supplier Discovery in Distributed Design and Manufacturing," in Proceedings of the 18th International Conference on Engineering Design (iced 11): Impacting Society Through Engineering Design, Vol 6: Design Information and Knowledge, vol. 6, S. J. Culley, B. J. Hicks, T. C. McAloone, T. J. Howard, and W. Chen, Eds. Glasgow: Design Soc, 2011, pp. 121-130.

[34] C. McArthur and F. Ameri, "Knowledge representation for supplier discovery in distributed manufacturing," in International Conference on Engineering Design, ICED11, 2011, pp. 1-11.

[35] V. Aravena-Diaz, R. Gacitua, H. Astudillo, and J. Labra-Gayo, "Identifying potential suppliers for competitive bidding using Latent Semantic Analysis," in Proceedings of the 2016 Xlii Latin American Computing Conference (clei), Valparaíso, Chile, Oct. 2016, pp. 1-12, doi: 10.1109/CLEI.2016.7833360.

[36] R. Davidrajuh and Z. Q. Deng, "Identifying potential supplier for formation of virtual manufacturing systems," 2000.

[37] S. J. Fenves, M. Mani, E. Subrahmanian, and A. T. Jones, "An enabler for supplier discovery in virtual supply chains: a shared terminology," NIST Inter-AgencyInternal Rep. NISTIR, p. 7647, 2009.

[38] Y. Kang, Extensible dynamic form for supplier discovery. Citeseer, 2011.

[39] Y. Kang, J. Kim, and Y. Peng, "Extensible Dynamic Form approach for supplier discovery," in 2011 IEEE International Conference on Information Reuse \& Integration, Las Vegas, NV, USA, Aug. 2011, pp. 83-87, doi: 10.1109/IRI.2011.6009525.

[40] J. Lee, K. Jung, B. H. Kim, Y. Peng, and H. Cho, "Semantic web-based supplier discovery system for building a long-term supply chain," Int. J. Comput. Integr. Manuf., vol. 28, no. 2, pp. 155169, Feb. 2015, doi: 10.1080/0951192X.2013.874594.

[41] J. Lee, K. Jung, B. H. Kim, and H. Cho, "Semantic Web-Based Supplier Discovery Framework," in Advances in Production Management Systems. Sustainable Production and Service Supply Chains, Berlin, 2013, vol. 414, pp. 477-484, doi: https://doi.org/10.1007/978-3-642-41266-0_57.

[42] C. Lee, Y. H. Lee, Y. Peng, and H. Cho, "A Supplier Discovery Framework for Effective and Efficient Configuration," Int. J. Ind. Eng. Theory Appl. Pract., vol. 18, no. 3, pp. 109-119, 2011, doi: doi:10.1115/DETC2010-28179.

[43] K. Im, J. Lee, B. Kim, Y. Peng, and H. Cho, "Conceptual framework of supplier discovery via ontology-driven semantic reasoning," in Proceedings of the 41st International Conference on Computers and Industrial Engineering, Los Angeles, California, USA, October, 2011, pp. 23-25.

[44] L. Mesmer and A. Olewnik, "Enabling supplier discovery through a part-focused manufacturing process ontology," Int. J. Comput. Integr. Manuf., vol. 31, no. 1, pp. 87-100, 2018, doi: 10.1080/0951192X.2017.1357837.

[45] A. Yamashita, R. Kutsuzawa, N. Takemura, J. Matsumoto, and N. Yamanaka, "Design of multi-dimensional search queries for efficient discovery of suppliers in the smart grid," in 2016 IEEE International Conference on Smart Grid Communications (SmartGridComm), Sydney, Australia, Nov. 2016, pp. 63-67, doi: 10.1109/SmartGridComm.2016.7778739.

[46] J. Bézivin, "On the unification power of models," Softw. Syst. Model., vol. 4, no. 2, pp. 171-188, 2005, doi: http://dx.doi.org/10.1007/s10270-005-0079-0.

[47] K. Czarnecki and S. Helsen, "Feature-based survey of model transformation approaches," IBM Syst. J., vol. 45, no. 3, pp. 621-630,632645, 2006.

[48] A. Montarnal, W. Mu, F. Benaben, J. Lamothe, M. Lauras, and N. Salatge, "Automated deduction of cross-organizational collaborative business processes," Inf. Sci., vol. 453, pp. 3049, Jul. 2018, doi: 10.1016/j.ins.2018.03.041.

[49] International Organization for Standardization, ISO/IEC 19510:2013 Information technology -Object Management Group Business Process Model and Notation. Geneva, Switzerland, 2013.

[50] F. Benaben et al., "Model-driven engineering of mediation information system for enterprise interoperability," Int. J. Comput. Integr. Manuf., pp. 1-22, Sep. 2017, doi: 10.1080/0951192X.2017.1379093.

[51] Tableau Software, "Tableau: Business Intelligence and Analytics Software." https://www.tableau.com/ (accessed Feb. 24, 2019). 